\title{
Environment Change and Sustainable Livelihoods in Ethnic Villages Tourism Development of China
}

\author{
Qianlang SHANG ${ }^{1}$, Mengxue LI and Huanhuan WANG \\ Tourism and Cultural Industry Research Institute, Yunnan University of Finance and \\ Economics, Kunming 650221, China
}

\begin{abstract}
The rapid development of ethnic tourism in China has led to changes in the social and economic environment and local livelihood strategies. This study aims to illustrate the environmental changes and the effects of livelihood strategies in ethnic tourism development. Based on the Sustainable Livelihood Approach (SLA), this study proposed the Sustainable Tourism Livelihood Framework (STLF) and designed the indicator system. The Jinglai ethnic tourism village case study showed the changing process and comparison of livelihood capitals with different livelihood strategies. The study found that the number of Tourism-based Strategies (TBS)and Tourism Strategies (TS) families increases, and the TS livelihood capital is the highest, and the Highly Participation Degree (HPD) family's capital is also higher. Meanwhile, family members have intergenerational differences in livelihood strategies. Finally, the suggestions about tourism community governance, such as environmental governance, knowledge training, and sustainable assessment, were proposed.
\end{abstract}

Keywords. Environmental governance, sustainable rural livelihoods, sustainable tourism livelihood framework

\section{Introduction}

The Chinese government has increased investment and policy encouragement in tourism during the past decade. The arrival of many tourists attracts residents to participate in tourism development, and higher tourism income further stimulates community families to carry out tourism business activities. Unlike traditional ethnic villages, which take planting and breeding as the main livelihood activities, the family livelihood activities in ethnic tourism communities gradually focus on tourism business activities. The family livelihood strategies have transformed, with a variety of family livelihood strategies coexisting.

Therefore, what is the relationship between environmental change and sustainable livelihoods? What kind of changing process have they experienced? What are the differences between families with different livelihood strategies? These questions need to be studied in depth.

Livelihoods comprise people and their capacities, assets, and activities required for a means of living [1]. Sustainable livelihood is the ability to restore and confront pressure

${ }^{1}$ Corresponding Author, Qianlang SHANG, Tourism and Cultural Industry Research Institute, Yunnan University of Finance and Economics, Kunming 650221, China; Email: shangqianlang@ynufe.edu.cn. 
and shocks, maintain capital, and keep growing based on conserving environmental resources. The DFID sustainable livelihood framework is currently widely adopted worldwide [2-4]. Research on tourism livelihoods primarily focuses on the application of SLA in tourism research $[5,6]$, and the relationship between tourism development and local livelihoods [7-9], livelihood changes in tourism development [10]. The neglect of culture in the SLA is a shortcoming [11]. The scholars have explored various methods to measure livelihood, including factor analysis [12], linear application regression [13], etc.

Therefore, based on SLA, this paper constructs an analysis framework of sustainable livelihood of ethnic tourism villages and designs an index system and data analysis methods. Taking Jinglai Village in Yunnan Province of China as a case, this paper reveals the transformation process of family livelihood strategies, the differences of different livelihood strategies, and the differences of different participation levels.

\section{Framework and Research Methods}

\subsection{Environment Change and STLF}

Although SLA has been widely used in tourism research, people have gradually realized the apparent defects of the framework, which is different from the tourism development environment. The specific manifestations are as follows: First, the application environment is different. The sustainable development of tourism is to consider destination tourism as a whole, while the sustainable livelihood approach focuses on the livelihood sustainability of individuals or families at the micro-level. Second, the concept of community is different. Community development has been paid more attention to the sustainable development of tourism, but the sustainable livelihood approach lacks attention to community development, criticized by many scholars. Third, the emphasis on culture is different. Traditional culture plays a prominent role in tourism development, especially in the development of ethnic tourism, and the relationship between family livelihood and traditional culture is inseparable. Therefore, SLA neglects cultural factors is considered a great regret [14].

So, this paper proposes the following viewpoints to improve the application of SLA and establish the Sustainable Tourism Livelihood Framework (STLF). First, Tourism Development Environment is an essential factor in the SLA framework. Secondly, STLF is constructed from two Community and Family levels. Community Livelihood is a group livelihood strategic choice made by the community based on capital, system, and culture, which affects the livelihood activities of most community residents and families. Thirdly, because of the critical role of tourism governance in tourism development, community governance, and livelihood change, Tourism Governance is included in the framework. Finally, take Cultural Capital as a component of livelihood capital assets.

The STLF includes Tourism Development Environment, Vulnerability, Institutional Arrangement, Livelihood Capital, Livelihood Strategy, Livelihood Outcomes, and family livelihood and community livelihood levels.

\subsection{Data Collection and Research Methods}

The research team conducted a preliminary investigation and formal investigation on the Jinglai village in March 2018, July 2018, and May 2019, using stakeholder interviews, family questionnaires, and participatory observation to collect data.

Semi-structured interviews and collective interviews mainly conduct interviews. 
This study lists three interview outlines for the central core stakeholders (tourism companies, village communities, and villagers). The total number of interviews with stakeholders and insiders is 24 .

The family questionnaire is based on the family livelihood capital, livelihood strategy, and livelihood results involved in the analysis framework, including five parts and 23 types of questionnaires processed by the Likert Scale. During the survey, 54 samples were obtained, and valid questionnaires were completed ( $48 \%$ of total).

Considering the construction and measurement of an index, the computational formula of livelihood capital is:

$$
C_{i}=\sum_{j=1}^{m} W_{j} X_{S_{i j}}
$$

In formula (1), $C_{i}$ represents the value of livelihood capital of sample $\mathrm{i} ; W_{j}$ represents the weight of $\mathrm{j} ; X_{S_{i j}}$ is the standardized value of sample $\mathrm{i}$ under index $\mathrm{j} ; \mathrm{m}$ is the index number.

Standardized value is nondimensionalized by range standardization, and the formula is

$$
X_{s_{i}}=\left(X_{i j}-X_{j_{\min }}\right) /\left(X_{j_{\max }}-X_{j_{\min }}\right)
$$

In formula (2), $X_{S_{i j}}$ represents the standardized value of sample $\mathrm{i}$ with index $\mathrm{j}$; $X_{i j}$ is the value of sample $\mathrm{i}$ with index $\mathrm{j} ; X_{j_{\max }}$ is the maximum of index $\mathrm{j}$, and $X_{j_{\min }}$ is the minimum of index $\mathrm{j}$.

In formula (1), using principal component analysis, the weight formula is:

$$
W_{P C A}=\frac{M}{N}
$$

In formula (3), $M$ is the scoring coefficient of primary factors, $N$ is the characteristic root; the index weight is determined according to all capital types, and $W_{P C A}$ needs to be normalized to obtain the corresponding index weight. The specific result was calculated by statistical software SPSS22.0.

\subsection{Environmental Change of Jinglai Village}

Jinglai Village is located in Xishuangbanna, Yunnan Province, southwest China. There are 112 households in Jinglai Village, 530 villagers, a typical Dai ethnic village. Scenic spots built by villages started in 2004 , were selected into the second batch of traditional Chinese villages in 2013, and were selected into the first batch of ethnic tourism villages of Yunnan Province of China in 2015 and China AAAA level scenic spots in 2018.

Traditionally, rice farming has been the main livelihood of residents. Tourism development has gradually become an important livelihood strategy in Jinglai since 2003. The livelihood strategies of Jinglai have undergone a change from traditional farming to a diversified livelihood mode. Especially after the development of tourism, the tourism livelihood activities in Jinglai have gradually become prominent and gradually become an essential local livelihood strategy and source of economic income. Take typical research on Jinglai to grasp the process of family livelihood changes, analyze the livelihood strategy choices of different families, and achieve the research goal of this paper. 


\section{Research Results}

\subsection{Tourism Business as an Important Livelihood Strategy}

The increase of tourists has changed the livelihood activities of families in Jinglai, and tourism activities have become the primary livelihood strategy of families (table 1). According to the survey, 15 families in Jinglai operate tourist inn services. Almost every household participates in small tourism commodities, including Dai costumes, tropical fruits, Myanmar specialties, winemaking, cloth art, pottery making. Seventy-two villagers went to work in the scenic spot, accounting for $60 \%$ of the total employees in the scenic spot. With the continuous expansion and construction of scenic spots, villagers have leased more land to the company.

Family livelihood strategy has experienced a transformation process from Agricultural Livelihood Strategy to other livelihood strategies, especially the tourism business. Meanwhile, family members have intergenerational differences in the choice of livelihood strategies.

Table 1. Livelihood activities before and after tourism development.

\begin{tabular}{lll}
\hline $\begin{array}{l}\text { Before tourism } \\
\text { Before 2003 }\end{array}$ & $\begin{array}{l}\text { After tourism } \\
2003-2013\end{array}$ & 2013-Now \\
\hline Main activities: & Main activities: & Main activities: \\
Rice, crops, and fruits & Rubber, Fruit, and Rice & $\begin{array}{l}\text { Tourism business } \\
\text { Scenic work }\end{array}$ \\
$\begin{array}{l}\text { Supplementary activities: } \\
\begin{array}{l}\text { Livestock, fishery, Migrant work, } \\
\text { rubber planting }\end{array}\end{array}$ & $\begin{array}{l}\text { Supplementary activities: } \\
\text { Livestock, Migrant work, Tourism }\end{array}$ & $\begin{array}{l}\text { Supplementary activities: } \\
\text { business, Scenic work, etc. }\end{array}$ \\
\hline
\end{tabular}

\subsection{Changes in Family Livelihood Assets}

According to the STLF, the family livelihood capital of Jinglai has changed before and after the tourism development. The overall level of livelihood capital has changed a lot. Different livelihood capital produces different livelihood strategies. Different livelihood capital determines the degree of family participation in tourism.

\subsection{Comparison of the Family with Different Strategies}

The previous article divided the family livelihood strategy into Agricultural Strategy (AS), Tourism-based Strategies (TBS), and Tourism Strategies (TS). According to the household questionnaire survey, among the 54 families, 46 are TS, and 8 are TBS, and there is no AS. TBS means that family members participate in tourism activities through scenic spot work, farmhouse entertainment, tourism commodities, and other means, and also engage in other livelihood activities such as agricultural planting, animal husbandry, part-time work, and business. TS families are mainly all members who are only engaged in tourism-related work.

According to the comparison results (table 2), TBS families' average total livelihood capital is 0.597 , lower than the average total livelihood capital of TS families of 0.605 . Among the six types of livelihood capital, the TS is higher than the TBS in human capital, natural capital, material capital, and cultural capital. 
Table 2. The family livelihood capital of different livelihood strategies.

\begin{tabular}{lll}
\hline Livelihood assets & \multicolumn{2}{l}{ Livelihood strategies } \\
\cline { 2 - 3 } & TS & TBS \\
\hline Human Capital & 0.141 & 0.13 \\
Natural Capital & 0.068 & 0.063 \\
Physical Capital & 0.113 & 0.109 \\
Social Capital & 0.169 & 0.179 \\
Financial Capital & 0.04 & 0.045 \\
Cultural Capital & 0.074 & 0.071 \\
Total & 0.605 & 0.597 \\
\hline
\end{tabular}

\subsection{Comparison of Family with Different Participation Levels}

According to the degree of family participation in tourism development, families in Jinglai can be divided into three types: Highly Participation Degree (HPD), Medium Participation Degree (MPD), and Low Participation Degree (LPD). HPD means that the livelihood activities of family members include at least one of four forms: scenic spot management personnel, farmhouse entertainment management, Dai catering, and scenic spot management committee. LPD refers to family members engaged in general staff in scenic spots and small commodity management. MPD is between the two others, which means that members are engaged in at least two kinds of tourism-related livelihood activities, such as general staff and small commodity management in scenic spots.

According to the household survey data, 10 families with HPD, accounting for $18.6 \%$; 15 families with MPD, accounting for $27.7 \%$; 29 families with LPD, accounting for $53.7 \%$.

Families with HPD have the highest total livelihood capital value (figure 1). HPD families score higher than the others in Physical Capital, Social Capital, Financial Capital, and Cultural capital. Meanwhile, MPD families show certain advantages in Human and Natura. However, the LPD families have lower scores in many aspects.

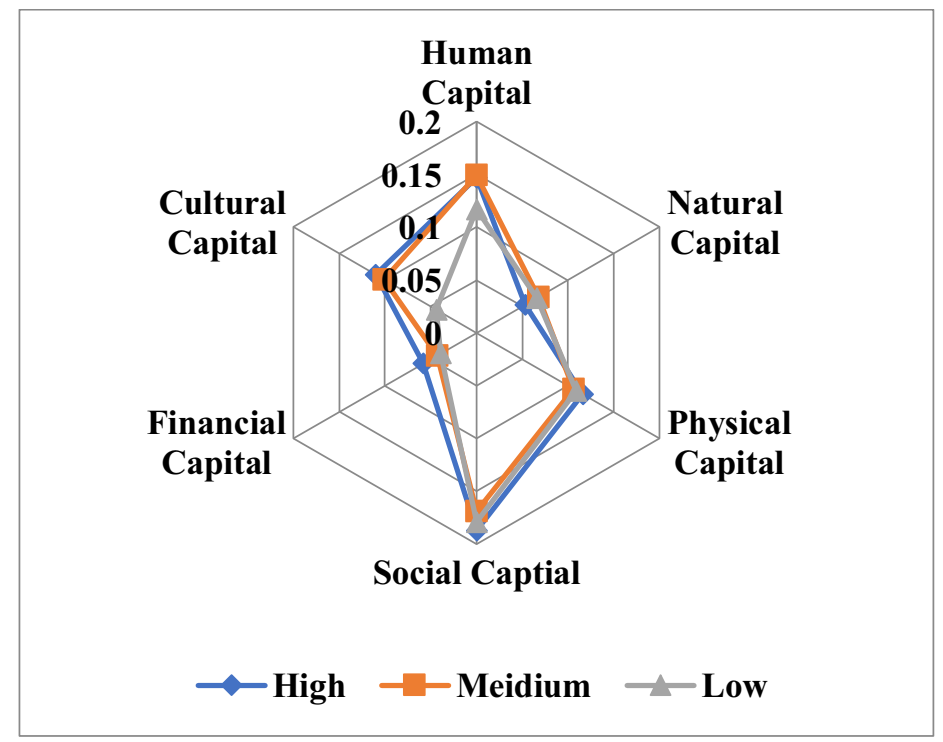

Figure 1. Family livelihood capital of different tourism participation levels. 


\section{Conclusions}

This research explores the relationship between environmental changes and sustainable livelihoods in ethnic tourism development. The empirical research of Jinglai Village based on the STLF and indicator system and measurement method that this paper proposed. The differences of livelihood capital under different livelihood strategies and different levels of tourism participation are discussed. The purpose is to explore the impact of tourism on family livelihoods and analyze the change process of family tourism livelihood strategies and different livelihood strategies.

The results show that the environmental change has contributed to the livelihood strategies transformation. With the rapid development of tourism, the livelihood strategies of local families have changed obviously, and different livelihood strategies have different choices. The research findings are as follows: Firstly, family tourismbased livelihood strategy has experienced a changing process from scratch. Secondly, family livelihood capital has changed significantly before and after tourism development. Thirdly, the total livelihood capital of families participating in tourism activities with TBS and TS is often higher than that of families. Forth, families with high levels of participation have the highest livelihood capital. Last but not least, there are internal intergenerational differences in the choice of livelihood strategies.

The main contributions of this study may as follows: Firstly, based on comparing the differences between SLA and tourism research, the STLF is constructed, which improves the theoretical basis of SLA in tourism research. Secondly, indicator systems and analysis methods are discussed, which is helpful to the application and realization of the STLF in specific case studies. Thirdly, the paper compares families with different livelihood strategies and different levels of tourism participation and improves the research on family livelihood strategies.

The study proposes the following suggestions for tourism community governance following by the results. The government and tourism management departments should educate the benefits and risks of villager's tourism business activities, correctly guide community residents to participate in tourism business activities, and avoid business bankruptcy caused by fluctuations in tourism development. Simultaneously, provided in developing tourism products and diversification of business activities, and villagers are encouraged to adopt diversified business strategies to reduce the risks of tourism livelihood activities.

\section{Acknowledgments}

This research was supported by the National Natural Science Foundation of China (72064039) and the Humanities and Social Sciences Research Project in 2020 of the Ministry of Education of China (20YJC630118).

\section{References}

[1] Chambers R and Conway G 1992 Sustainable rural livelihoods: Practical concepts for the 21st century Livelihoods (UK: Institute of Development Studies) Chapter 2 5-6.

[2] Ashley C and Carney D 1999 Sustainable livelihoods: Lessons from early experience Practical Applications (London, UK: DFID) Chapter 217. 
[3] Scoones I 2007 Sustainability Development in Practice 17 (4-5) 589-596.

[4] Simpson M C 2009 An integrated approach to assess the impacts of tourism on community development and sustainable livelihoods Community Development Journal 44 (2) 186-208.

[5] Tao T C H and Wall G 2009 Tourism as a sustainable livelihood strategy Tourism Management 30 (1) 90-98.

[6] $\mathrm{Su} \mathrm{M} \mathrm{M,} \mathrm{Wall} \mathrm{G} \mathrm{and} \mathrm{Xu} \mathrm{K} 2016$ Heritage tourism and livelihood sustainability of a resettled rural community: Mount Sanqingshan World Heritage Site, China Journal of Sustainable Tourism 24 (5) 735 757.

[7] Simpson M C 2007 Tourism, livelihoods, biodiversity, conservation and the climate change factor in developing countries Climate Change and Tourism: Assessment and Coping Strategies 189-207.

[8] Buckley R, Shakeela A and Guitart D 2014 Adventure tourism and local livelihoods Annals of Tourism Research 48 (C) 269-272.

[9] Su M M, Wall G, Wang Y, et al. 2019 Livelihood sustainability in a rural tourism destination-Hetu Town, Anhui Province, China Tourism Management 71 272-281.

[10] Mbaiwa J E 2011 Changes on traditional livelihood activities and lifestyles caused by tourism development in the Okavango Delta, Botswana Tourism Management 32 (5) 1050-1060.

[11] Shen F, Hughey K F D and Simmons D G 2008 Connecting the sustainable livelihoods approach and tourism: A review of the literature Journal of Hospitality and Tourism Management 15 (1) 19-31.

[12] Powell R B, Green T F, Holladay P J, et al. 2018 Examining community resilience to assist in sustainable tourism development planning in Dong Van Karst Plateau Geopark, Vietnam Tourism Planning \& Development 15 (4) 436-457.

[13] Ahebwa W M, Aporu J P and Nyakaana J B 2016 Bridging community livelihoods and cultural conservation through tourism: Case study of Kabaka heritage trail in Uganda Tourism and Hospitality Research 16 (2) 103-115.

[14] Daskon C and Binns T 2010 Culture, tradition and sustainable rural livelihoods: exploring the culturedevelopment interface in Kandy, Sri Lanka Community Development Journal 45 (4) 494-517. 